\title{
Eco-friendly approach in synthesis of silver nanoparticles and evaluation of optical, surface morphological and antimicrobial properties
}

\author{
Venilla Selvaraj ${ }^{1}$ Suresh Sagadevan ${ }^{2} \cdot$ Lakshmipathy Muthukrishnan $^{3} \cdot$ Mohd. Rafie Johan $^{2} \cdot$ Jiban Podder $^{4}$
}

Received: 16 March 2019 / Accepted: 22 May 2019 / Published online: 29 May 2019

(c) The Author(s) 2019

\section{Abstract}

Silver nanoparticles (Ag NPs) were synthesized using Alternanthera sessilis leaf and Oregano root extract in an eco-friendly fashion and their significant physicochemical and optochemical properties were ascertained for nano-defined characteristics. The UV-visible spectrum showed a single and distinct absorbance peak at $433 \mathrm{~nm}$ (Alternanthera sessilis) and $425 \mathrm{~nm}$ (Oregano), typical SPR (surface plasmon resonance) for silver. Structural studies revealed nano-crystal with face centre cubic (FCC) symmetry with monodispersed nature. SEM studies showed spherical-shaped particles and the purity determined from EDX spectrum. The synthesized Ag NPs showed that antibacterial activity was studied. There was a significant inhibitory effect toward clinically important pathogens viz. B. subtilis, S. aureus, P. aeruginosa, and E. coli exposed to Ag NPs at different concentrations.

Graphic abstract

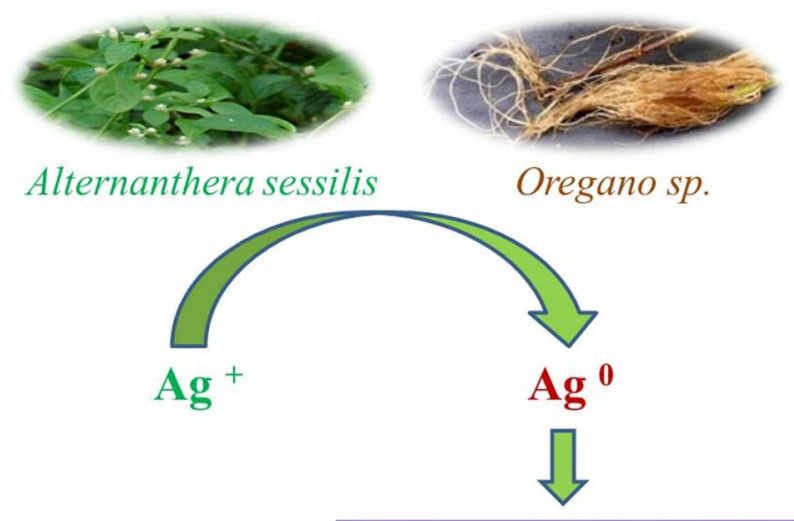

Optical Characterization

Surface Morphology

Antimicrobial efficacy

Biomedical applications

Keywords Green synthesis · Silver nanoparticles · Alternanthera sessilis · Oregano · Antimicrobial activity

Extended author information available on the last page of the article 


\section{Introduction}

Manoevering of particles at nanoscale tends to gain unique properties for use in various applications, viz., nano-generators, drug delivery system, and medical imaging [1-4]. Their efficiency to improve solubility, half-life, and sustained release of drugs find its application more appropriate in drug delivery [5]. In the current situation, the nano-biotechnology is one among the most energetic platform, explore the contemporary substantial discipline where the plants and various plant products find an imperious use in the fabrication of nanoparticles [6]. As vast applications of nanomaterials in various fields such as electronic, magnetic, optoelectronics, and information storage are well established. Researchers have found the remarkable application of nanomaterial in the field of medicine such as antimicrobial activity. The existing drug of choice is now becoming a major threat across the globe leading to the emergence of drug-resistant microbes or superbugs challenging the survival of humans. Therefore, to counteract the situation, researchers are on the verge of finding an alternate drug [7]. One such strategy is by the use of metals such as copper, zinc, titanium, magnesium, gold, etc., which, in their nano-form, are considered to exhibit remarkable physical, chemical, and biological properties. To counterbalance the situation, antimicrobial properties of the metallic nanoparticles have been explored to contain resistant strains [8]. Amongst them, silver nanoparticles are found to exhibit unique properties such as conductivity, chemical stability, and catalytic and biological (antibacterial, antiviral, antifungal, and anti-inflammatory) activities [9]. Despite various other methods of synthesizing nanoparticles, the eco-benign approach has been the most sought after. Besides, microbial synthesis, plant product/phytochemicalmediated synthesis of nanoparticles has drawn much attention because of its availability, reproducibility, and reliability [10-17]. This study reports on the eco-friendly green syntheses of silver nanoparticles (Ag NPs) using two plant extracts such as Alternanthera sessilis leaf and Oregano root extracts as a reduction agent. In our study, the role of the extracts in reducing $\mathrm{Ag}^{+}$to $\mathrm{Ag}^{0}$ has been investigated through spectroscopic and microscopic analyses emphasizing the antibacterial efficacy. The schematic representation of Ag NPs extracted from plants, as shown in Fig. 1.

\section{Materials and methods}

\section{Materials}

Alternanthera sessilis leaves were procured from a local market in periyakulam, and silver nitrate $\left(\mathrm{AgNO}_{3} \geq 99.8 \%\right.$;

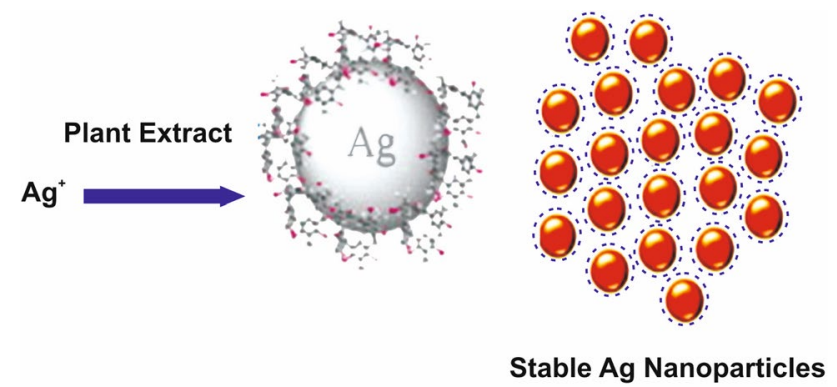

Fig. 1 Schematic representation of the synthesis of silver nanoparticles

AR grade) was purchased from Sigma-Aldrich and used without further purification. All the glass wares used were cleaned in chromic acid and autoclaved.

\section{Preparation of the extracts of Alternanthera sessilis and Oregano root}

$50 \mathrm{~g}$ of fresh Alternanthera sessilis leaves and Oregano root were thoroughly washed in running water followed by distilled water to remove any dust particles. They were initially dried on an absorbent paper and chopped into small pieces using a pair of scissors. Prior to surface cleansing, Alternanthera sessilis leaves and Oregano roots were blended separately in a mixer grinder for less than a minute with $10 \mathrm{~mL}$ of distilled water. The blending was checked for paste-like consistency and collected in two separate Erlenmeyer flasks. To the pastes, $100 \mathrm{~mL}$ of double distilled water was added and kept in a shaking incubator at $80{ }^{\circ} \mathrm{C}$ for $10 \mathrm{~min}$. Both the mixtures were brought down to room temperature and subjected to filtration using syringe filter (pore size $0.2 \mu \mathrm{m}$ ) and the filtrate maintained at $4{ }^{\circ} \mathrm{C}$.

\section{Synthesis of Ag NPs by Alternanthera sessilis leaf and Oregano root extracts}

To $100 \mathrm{~mL}$ of $1 \mathrm{mM}$ silver nitrate taken in two separate flasks, $5-10 \mathrm{~mL}$ of Alternanthera sessilis leaf and Oregano extracts were added under the stirring condition for $20 \mathrm{~min}$ at $60{ }^{\circ} \mathrm{C}$. Reaction pertaining to nanoparticle synthesis with respect to time was observed. Furthermore, separation and purification of the colloids were performed using repeated washing and centrifugation. Finally, the particles were dried and stored in airtight containers for further experiment.

\section{Characterization Techniques}

UV-Vis Schimadzu 1800 spectrophotometer was used to record the absorbance spectrum $(200-700 \mathrm{~nm})$ of the synthesized silver nanoparticles operated at a resolution of 
$1 \mathrm{~nm}$. The phase purity of synthesized silver nanoparticles was determined using a Philips X'pert Pro diffractometer (Schimadzu) aided with $\mathrm{CuK} \beta$ radiation. FT-IR spectrum was recorded on JASCO 4400 in the spectral range of $4000-400 \mathrm{~cm}^{-1}$ with sample pelleted using potassium bromide (1:100). Electron microscopic studies (Carl Zeiss MA15) were performed on the sample sputtered with gold to analyze the surface properties and assembly characteristics. The composition of the synthesized silver nanoparticles was determined using X-ray Energy Dispersion Spectroscopy (Inca, Oxford Instruments, Buckinghamshire, UK).

\section{Antibacterial activity}

The antimicrobial activity of phytochemically synthesized silver colloids was determined using agar diffusion method using clinically important pathogens containing Gram-positive and Gram-negative test strains. The pure cultures of the strains at $1 \times 10^{8} \mathrm{CFU} / \mathrm{mL}$ were swabbed uniformly onto the Mueller-Hinton agar (MHA) medium using sterile swabs. Four hollow blocks of medium (dia $6 \mathrm{~mm}$ ) were cut from the MHA plates using $100 \mu \mathrm{L}$ sterile pipette tips. Ag NPs synthesized from two different extracts at a concentration of 25,50 , and $75 \mu \mathrm{L}$ was added to the wells using a sterile micropipette. Amoxicillin antibiotic $(25 \mu \mathrm{L})$ was used as a positive control. The culture-inoculated plates treated with Ag NPs and antibiotic were incubated for $18-24 \mathrm{~h}$ at $37^{\circ} \mathrm{C}$ for the observation of any inhibition zone.

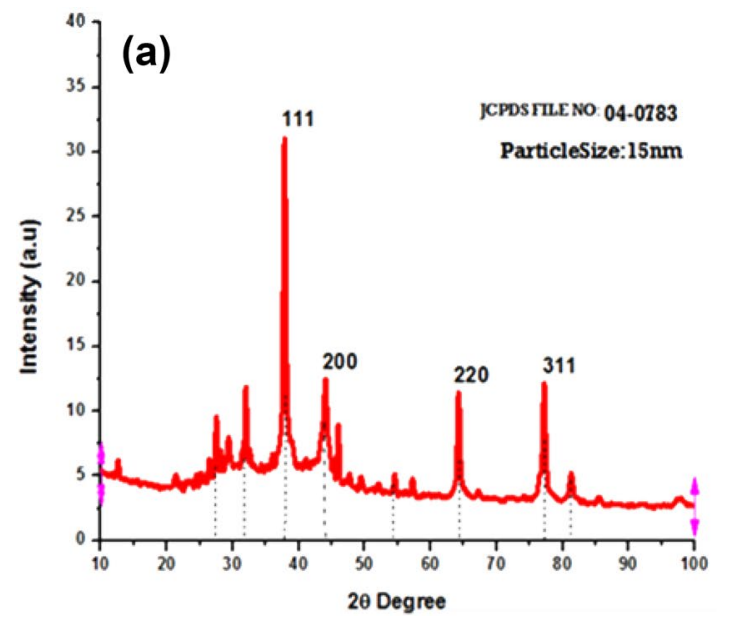

Fig. 2 XRD pattern of plant extracted from $\mathbf{a}$ ASL and $\mathbf{b}$ OR of Ag NPs

\section{Results and discussion}

\section{Structural analysis}

The typical XRD pattern of silver nanoparticles synthesized using a leaf and root extracts of Alternanthera sessilis and Oregano root, respectively, is shown in Fig. 2a, b. Both ASL- and OR-mediated synthesis showed diffraction peaks at $2 \theta=38.2^{\circ}, 44^{\circ}, 64.4^{\circ}$, and $77.2^{\circ}$ corresponding to (111), (200), (220), and (311) that can be assigned to face centered cubic symmetry (fcc) [18]. These diffraction patterns were compared and found closely associated to JCPDS No. 04-0783 [19]. The robust intensity of diffraction at $38^{\circ}$ indicated silver crystal's preferential orientation along (111) plane. In addition, we could observe a peak at $2 \theta=46.3^{\circ}$ which might have been associated with bio-organic phase crystallization [20]. The mean crystallite size of the silver nanoparticles was calculated from Scherrer's formula [21]:

$D=\frac{0.9 \lambda}{\beta \cos \theta}$,

where $D$ denotes mean crystallite size of the nanoparticle, $\lambda$ denotes wavelength of X-ray, $\beta$ accounts for full width at half maximum intensity (FWHM), and $\theta$ represent Bragg's angle. Accordingly, the mean crystal size of the ASL- and OR-mediated nanoparticle synthesis worked out to $19 \mathrm{~nm}$ and $10 \mathrm{~nm}$.

\section{Optical studies}

A dark brown suspension of colloids was formed after the addition of the extracts to the reaction mixture. This dark brown color may be due to the collective vibrations of the charged particles present on the surface of nanoparticles

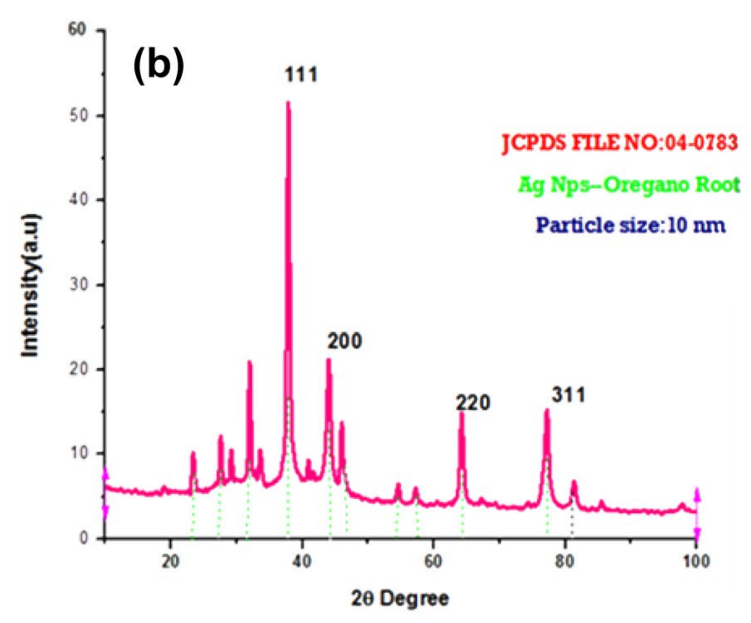


Fig. 3 UV absorption spectra of a ASL, b synthesis Ag NPs from ASL extract, and c OR and d synthesis Ag NPs from OR extract

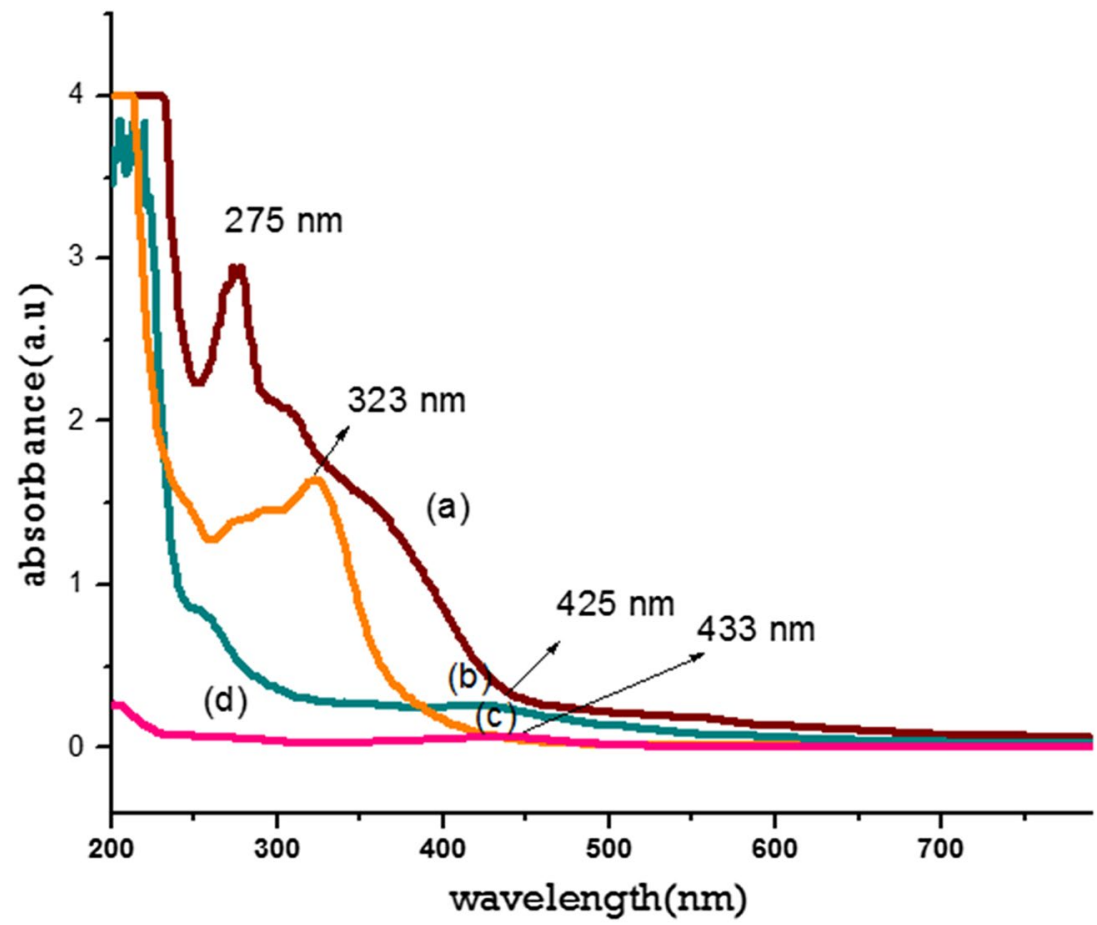

and the resonance [22-24]. A sharp and a narrow distinct peak at $\lambda_{\max }=433 \mathrm{~nm}$ in the visible region clearly elucidate the formation of Ag NPs in a short duration (10-15 min) after the addition of ASL extract as in Fig. 3a, b [25]. Similarly, UV-visible spectra recorded an absorbance of $425 \mathrm{~nm}$ within 10 min of addition of OR extract as in Fig. 3c, d.

\section{SEM and EDX analysis}

The morphology and the elemental composition of Ag NPs were observed using SEM and EDX studies as shown in Figs. 4 and 5. Electron micrograph revealed sphericalshaped particles with a smooth surface and closely arranged [26]. The size of Ag NPs synthesized using ASL and OR extract was around $23.44 \mathrm{~nm}$ and $17.58 \mathrm{~nm}$, respectively, which is in good agreement with the crystallite size as inferred by XRD. The elemental composition as demonstrated from EDX spectra revealed a strong signal for silver. In addition, carbon, oxygen, and nitrogen signals could also be detected. Carbon signal might have resulted from the grid, oxides during sample preparation, and nitrogen might have been a phytochemical moiety responsible for capping nanoparticle as shown in inset Figs. 4 and 5.

\section{Fourier transform infrared spectroscopy (FT-IR)}

FT-IR spectroscopy exhibited the possible biomolecular interaction in the formation of nanoparticles using ASL and OR (Fig. 6a, d. The FT-IR spectra of OR Ag NPs showed prominent peaks at $3452 \mathrm{~cm}^{-1}, 2072 \mathrm{~cm}^{-1}, 1634 \mathrm{~cm}^{-1}$, and
$642 \mathrm{~cm}^{-1}$ attributing $\mathrm{N}-\mathrm{H}$ asymmetric stretching assigned to Amide group, $\mathrm{C}=\mathrm{C}$-stretching vibration denoting Alkyne group, $\mathrm{N}-\mathrm{H}$ bend indicating primary amine group, and $\mathrm{C}-\mathrm{Br}$ stretching vibration indicating the Alkyl halide group. A peak residing at $655 \mathrm{~cm}^{-1}$ represented a key component responsible for the reduction and capping of the extract with that of metal by their intermolecular interaction [27]. The sharp absorption peak at $664 \mathrm{~cm}^{-1}$ can be attributed due to $\mathrm{C}-\mathrm{Cl}$ stretching for halogen compounds, the alcohol and phenols stretching of $\mathrm{C}-\mathrm{O}$ bond occur at $1074 \mathrm{~cm}^{-1}$, the band at $1615 \mathrm{~cm}^{-1}$ exist due to $\mathrm{C}=\mathrm{O}$ stretch of tertiary amides, and the broad peak at $3426 \mathrm{~cm}^{-1}$ is the characteristic $\mathrm{O}-\mathrm{H}$ stretching for alcohols and phenols. In addition, the functional biomolecules in ASL extract were hydroxyl, carboxylic, phenol, and amine groups involved in silver ion reduction. Thus, biological molecules enforce the dual role of formation and stabilization of Ag NPs in the aqueous medium [28].

\section{Antimicrobial assay}

The antimicrobial activity of ASL- and OR-mediated Ag NPs is elaborated in Figs. 7 and 8. There was a significant inhibition of growth of bacteria tested. ASL-mediated Ag NPs showed the maximum inhibition zone against Staphylococcus aureus $(11 \mathrm{~mm})$ followed by Pseudomonas aeruginosa $(10 \mathrm{~mm})$, Escherichia coli (9 mm), and Bacillus subtilis (4 mm). OR-mediated Ag NPs susceptibility pattern showed a maximum zone toward Pseudomonas 


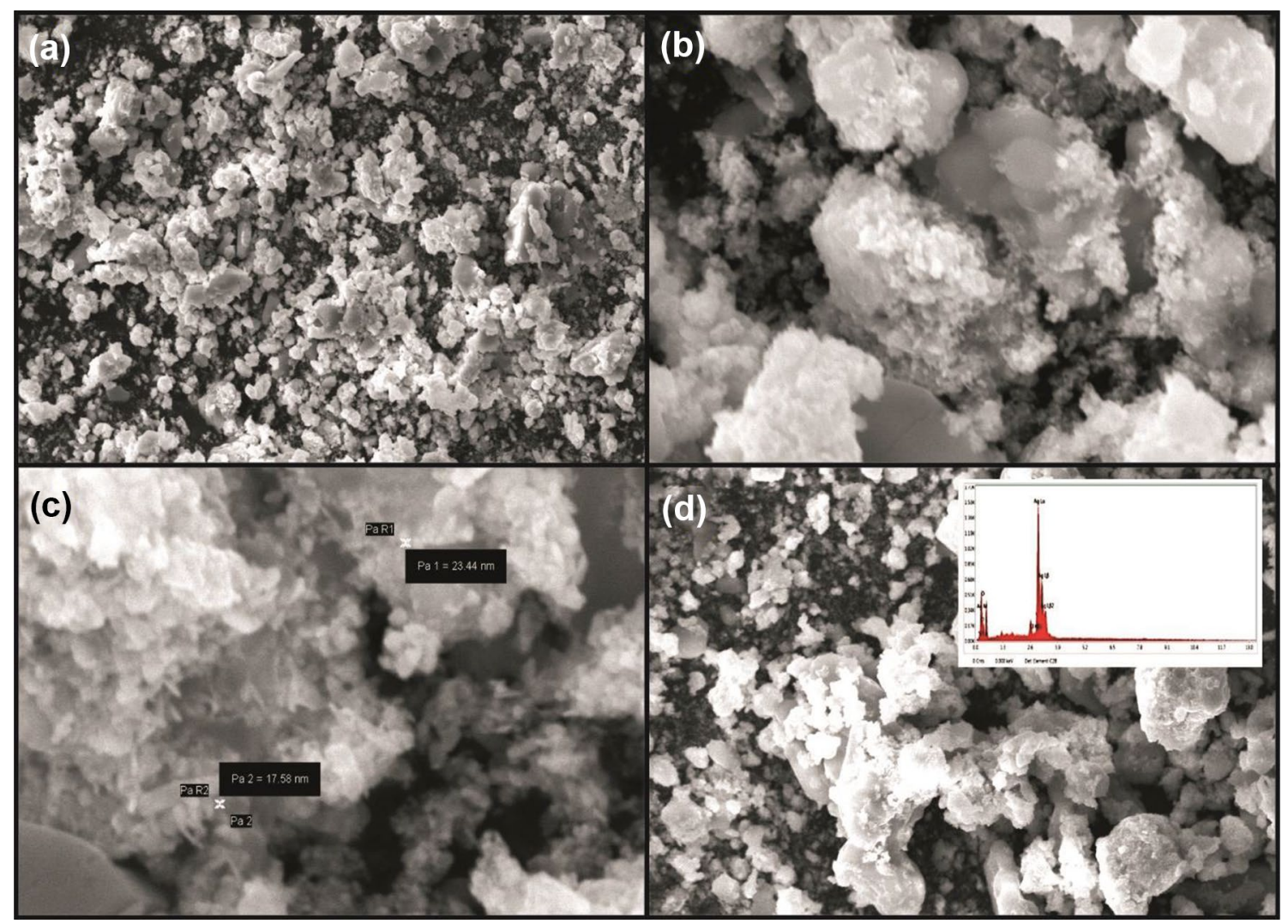

Fig. 4 SEM with EDX images of plants extracted from ASL of Ag NPs

aeruginosa (6 $\mathrm{mm})$ followed by Escherichia coli $(5 \mathrm{~mm})$, Bacillus subtilis $(4 \mathrm{~mm})$, and Staphylococcus aureus (3 mm).

Antibacterial mechanism exhibited by metal nanoparticles depends on the degree of susceptibility of microbes. The nanoparticles when encountered with the microbe adhere to the bacterial surface via electrostatic interaction. Their significantly smaller size helps gain entry into the bacterial cell via the transmembrane proteins and by the influence of proton motive force. It has a greater affinity towards sulfur groups present in proteins to form thiols [29] and on phosphates forming complexes resulting in DNA damage. It was demonstrated that Ag NPs' interaction with cysteine residues results in the generation of ROS by inhibiting electrons at terminal oxidase, thereby inducing bacterial cell death. The difference in susceptibility pattern toward Ag NPs exposed to Gram-positive and Gram-negative strains relies on their cell wall make up. Gram-positive strains possess a thick cell wall made of peptidoglycan that helps to prevent intrusion of foreign body selectively, whereas the Gram-negative strain lacks such component that falls easy prey to an antimicrobial agent, in this case, Ag NPs, which sustains severe damage leading to cell death [30-33].

\section{Conclusions}

The present work highlights the most simple and economical approach in the synthesis of Ag NPs using plant extracts of Alternanthera sessilis (leaf) and Oregano (root) as reducing agents. Spectroscopic and Microscopic analyses revealed typical nano-characteristics of silver. FT-IR results confirmed the contribution of phytochemicals, viz., terpenes, flavonoids, and proteins for effective synthesis. There was a significant bactericidal activity against Bacillus subtilis, Staphylococcus aureus, Pseudomonas aeruginosa, and Escherichia coli as evidenced from agar welldiffusion method. This biosynthesized Ag NPs represented a promising antimicrobial with potential biomedical applications. Therefore, this green chemistry approach towards the synthesis of Ag NPs has been the most sought-after method in terms of economic viability. 


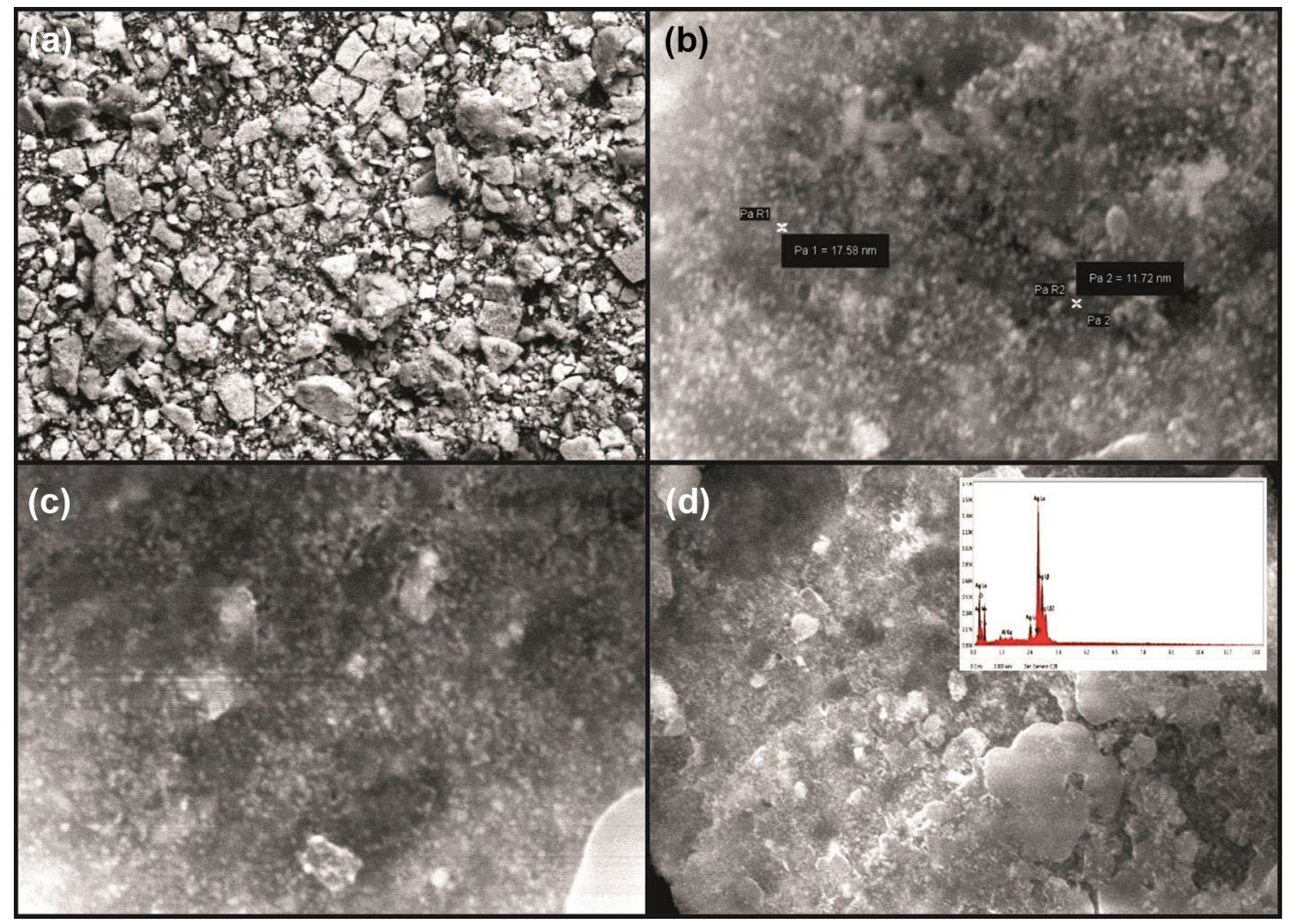

Fig. 5 SEM with EDX images of plants extracted from OR of Ag NPs

Fig. 6 a OR-mediated silver nanoparticles, b OR extract, c ASL extract-mediated silver nanoparticles, and d ASL extract

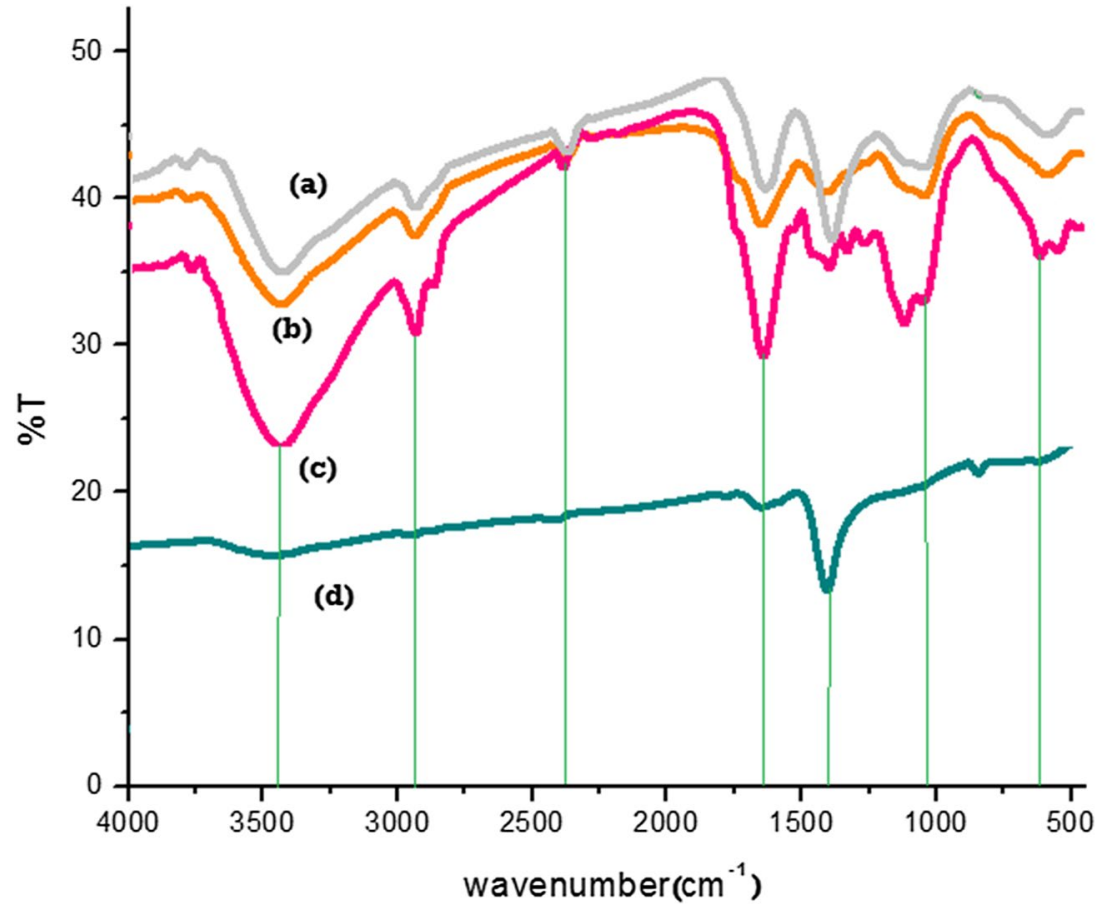




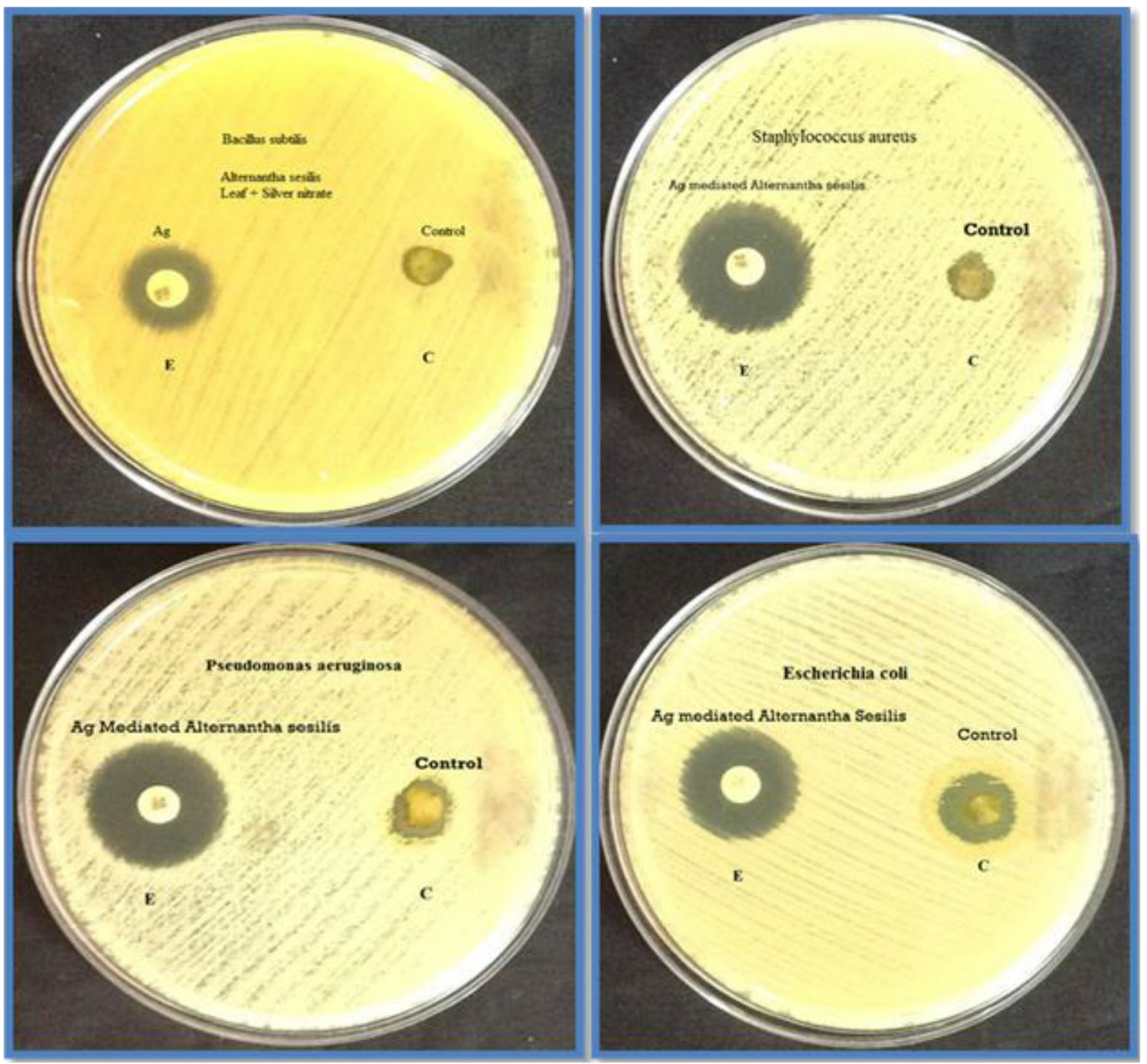

Fig. 7 Antimicrobial activity of Alternanthera leaf extract of silver nanoparticles 


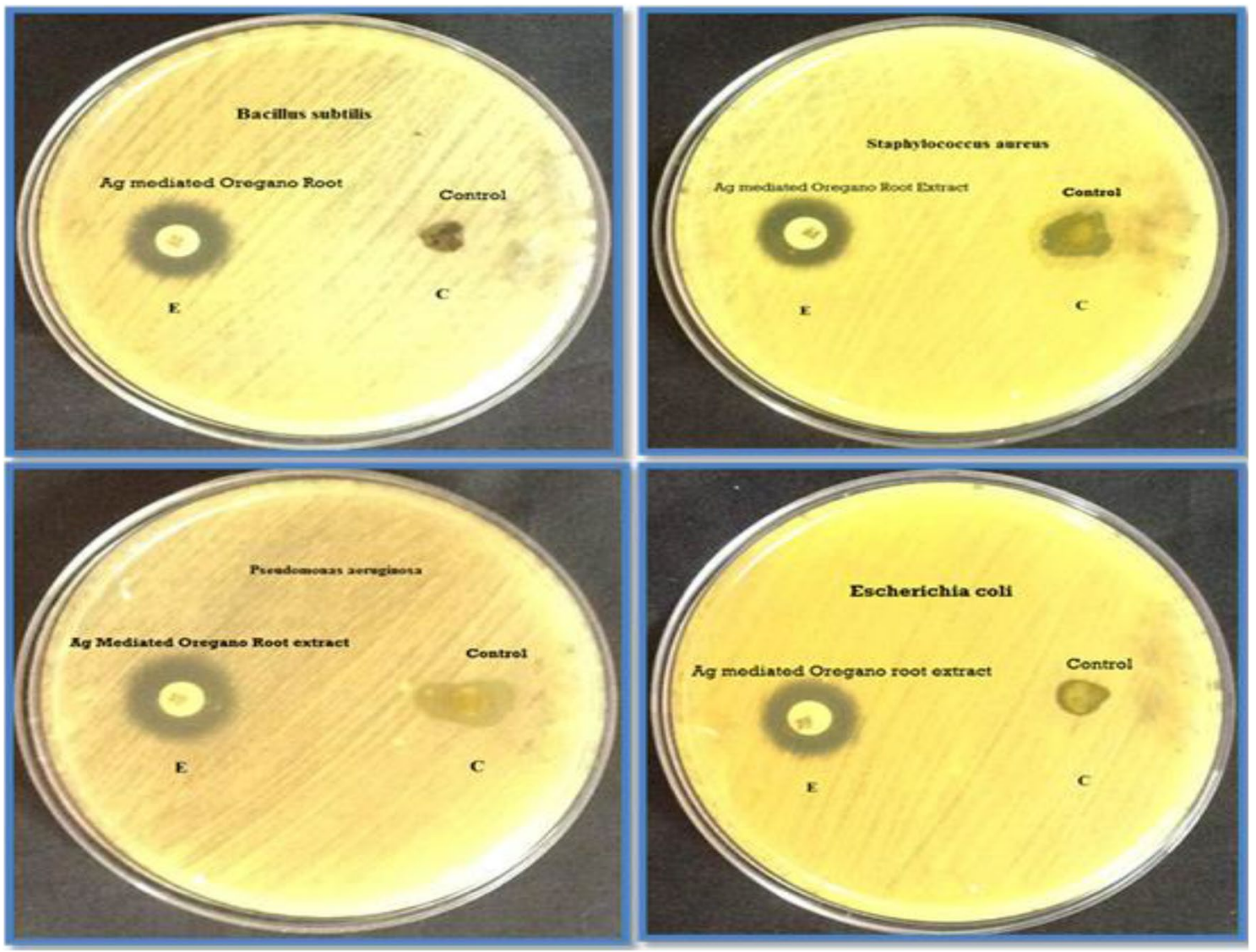

Fig. 8 Antimicrobial activity of Oregano root extract of silver nanoparticles

Acknowledgements One of the authors (Suresh Sagadevan) acknowledges the honor, namely the "Senior Research Fellow" at Nanotechnology \& Catalysis Research Centre (NANOCAT), University of Malaya 50603 Kuala Lumpur, Malaysia. The author wishes to place on record his heartfelt thanks that are due to the authorities concerned.

\section{Compliance with ethical standards}

Conflict of interest The authors declare no conflict of interest.

Open Access This article is distributed under the terms of the Creative Commons Attribution 4.0 International License (http://creativecommons.org/licenses/by/4.0/), which permits unrestricted use, distribution, and reproduction in any medium, provided you give appropriate credit to the original author(s) and the source, provide a link to the Creative Commons license, and indicate if changes were made.

\section{References}

1. De-Zhi, L., Hong-Da, C., Feng, B., Zhen-Xin, W.: Progress of multimodal molecular imaging technology in diagnosis of tumor. Chin. J Anal. Chem. 44, 1609-1618 (2016). https://doi. org/10.1016/S1872-2040(16)60966-0
2. Ujjal Kumar, S., Balaprasad, A., Sanat, K., Animesh, H., Pulak, D.: Green synthesis of silver nanoparticles using the plant extract of Shikakai and Reetha. Mater. Today Proc. 5, 2321-2329 (2018). https://doi.org/10.1016/j.matpr.2017.09.236

3. Thombre, R., Mehta, S., Mohite, J., Jaisinghani, P.: Synthesis of silver nanoparticles and its cytotoxic effect against thp-1 cancer cell line. Int. J. Pharma Bio Sci. 4(1), 184-192 (2013)

4. Naraginti, S., Li, Y.: Preliminary investigation of catalytic, antioxidant, anticancer and bactericidal activity of green synthesized silver and gold nanoparticles using Actinidia deliciosa. J. Photochem. Photobiol. B 170, 225-234 (2017). https://doi. org/10.1016/j.jphotobiol.2017.03.023

5. Dakshayani, S.S., Marulasiddeshwara, M.B., Ramesh, M.N.S., Raghavendra Kumar, P., Devaraja, S.R.H.K.: Antimicrobial, anticoagulant and antiplatelet activities of green synthesized silver nanoparticles using Selaginella (Sanjeevini) plant extract. Int. J. Biol. Macromol. 131, 787-797 (2019). https://doi.org/10.1016/j. ijbiomac.2019.01.222

6. Zahra, H.P., Hossein, A., Naser, K., Ali, F.: Eco-Friendly synthesis and antimicrobial activity of silver nanoparticles using Dracocephalum moldavica seed extract. Appl. Sci. 6, 69 (2016). https ://doi.org/10.3390/app6030069

7. Marulasiddeshwara, M.B., Dakshayani, S.S., Sharath Kumar, M.N., Chethana, R., Raghavendra Kumar, P., Devaraja, S.: Facile-one pot-green synthesis, antibacterial, antifungal, antioxidant and antiplatelet activities of lignin capped silver nanoparticles: a promising therapeutic agent. Mater. Sci. Eng. C Mater. Biol. Appl. 81, 182-190 (2017). https://doi.org/10.1016/j.msec.2017.07.054 
8. Khalil, K.A., Fouad, H., Elsarnagawy, T., Almajhdi, F.N.: Preparation and characterization of electrospun PLGA/silver composite nanofibers for biomedical applications. Int. J. Electrochem. Sci. 8, 3483-3493 (2013)

9. Kamiar, Z., Seyedmohammad, P., Arman, S., Pouyan, M., Keyvan, P., Mohammad, J.R., Ali, A.M.: Biosynthesis and characterization of silver nanoparticles by Aspergillus species. BioMed. Res. Int. (2016). https://doi.org/10.1155/2016/5435397

10. Nakkala, J.R., Mata, R., Gupta, A.K., Sadras, S.R.: Biological activities of green silver nanoparticles synthesized with Acorus calamus rhizome extract. Eur. J. Med. Chem. 85, 784-794 (2014). https://doi.org/10.1016/j.ejmech.2014.08.024

11. Nabikhan, A., Kandasamy, K., Raj, A., Alikunhi, N.M.: Synthesis of antimicrobial silver nanoparticles by callus and leaf extracts from saltmarsh plant, Sesuvium portulacastrum L. Colloids Surf B Biointerfaces. 79(2), 488-493 (2010). https://doi.org/10.1016/j. colsurfb.2010.05.018

12. Ulug, B., Haluk, Turkdemir, Cicek, A., Mete, A.: Role of irradiation in the green synthesis of silver nanoparticles mediated by fig (Ficus carica) leaf extract. Spectrochim. Acta A Mol. Biomol. Spectrosc. 25(135), 153-161 (2015). https://doi.org/10.1016/j. saa.2014.06.142

13. Hossam, E.E., Manal, M.E., Hanan, B.A.: One-pot fabrication of AgNPs, AuNPs and Ag-Au nano-alloy using cellulosic solid support for catalytic reduction application. Carbohydr. Polym. 166, 1-13 (2017). https://doi.org/10.1016/j.carbpol.2017.02.091

14. Yosari, S., Pontaza-Licona Ramos-Jacques, A.L., CervantesChavez, J.A., Luis López-Miranda, J., Álvaro de Jesús, R.B., Maya-Cornejo, J., Rodríguez-Morales, A.L., Esparza, R., Estevez, M., Pérez, R., Hernandez-Martínez, A.R.: Alcoholic extracts from Paulownia tomentosa leaves for silver nanoparticles synthesis. Results Phys. 12, 1670-1679 (2019). https://doi.org/10.1016/j. rinp.2019.01.082

15. Rocha-Rocha, O., Cortez-Valadez, M., Hernandez-Martinez, A.R., Gamez-Corrales, R., Alvarez, R.A.B., Britto-Hurtado, R., Delgado-Beleño, Y., Martinez-Nuñez, C.E., Pérez-Rodríguez, A., Arizpe-Chávez, H., Flores-Acosta, M.: Green synthesis of Ag-Cu nanoalloys using Opuntia ficus-indica. J. Electron. Mater. 46, 802 (2017). https://doi.org/10.1007/s11664-016-4942-2

16. Haydé, V.C., Granados-Segura, L.O., Gabriel, L.B., David, J.M., María, G.H., Noe, A., Angel, R., Miriam, E., Héctor, P.: Gold nanoparticles bioreduced by natural extracts of arantho (Kalanchoe daigremontiana) for biological purposes: physicochemical, antioxidant and antiproliferative evaluations. Mater. Res. Express 6, 055010 (2019). https://doi.org/10.1088/2053-1591/ab0155

17. Geetha, R., Thirunavukkarasu, A., Tamilselvan, S., Govindaraju, K., Sadiq, M., Singaravelu, G.: Green synthesis of gold nanoparticles and their anticancer activity. Cancer Nanotechnol. (2013). https://doi.org/10.1007/s12645-013-0040-9

18. Roy, K., Sarkar, C.K., Ghosh, C.K.: Plant-mediated synthesis of silver nanoparticles using parsley (Petroselinum crispum) leaf extract: spectral analysis of the particles and antibacterial study. Appl. Nanosci. 5, 945-951 (2015). https://doi.org/10.1007/s1320 4-014-0393-3

19. Elumalai, D., Hemavathi, M., Deepaa, C.V., Kaleena, P.K.: Evaluation of phytosynthesised silver nanoparticles from leaf extracts of Leucas aspera and Hyptis suaveolens and their larvicidal activity against malaria, dengue and filariasis vectors. Parasite Epidemiol. Control. 2(4), 15-26 (2017). https://doi.org/10.1016/j.parep i.2017.09.001

20. Mallikarjuna, K., Sushma, N.J., Narasimha, G., Manoj, L., Raju, B.D.P.: Phytochemical fabrication and characterization of silver nanoparticles by using Pepper leaf broth. Arab. J. Chem. 7, 10991103 (2014). https://doi.org/10.1016/j.arabjc.2012.04.001

21. Rajkumar, P.V., Ravichandran, K., Baneto, M., Ravidhas, C., Sakthivel, B., Dineshbabu, N.: Enhancement of optical and electrical properties of SILAR deposited $\mathrm{ZnO}$ thin films through fluorine doping and vacuum annealing for photovoltaic applications. Mater. Sci. Semicond. Process. 35, 189-196 (2015). https://doi. org/10.1016/j.mssp.2015.03.010

22. Ahamed, M., Khan, M.A.M., Siddiqui, M.K.J., AlSalhi, M.S., Alrokayan, S.A.: Green synthesis, characterization, and evaluation of biocompatibility of silver nanoparticles. Phys. E Low Dimens. Syst. Nanostruct. 43(6), 1266-1271 (2011). https://doi. org/10.1016/j.physe.2011.02.014

23. Krishnaraj, C., Jagan, E.G., Rajasekar, S., Selvakumar, P., Kalaichelvan, P.T., Mohan, N.: Synthesis of silver nanoparticles using Acalypha indica leaf extracts and its antibacterial activity against water borne pathogens. Colloids Surf. B Biointerfaces 76(1), 50-56 (2010). https://doi.org/10.1016/j.colsurfb.2009.10.008

24. de Matos, R.A., da Silva Cordeiro, T., Samad, R.E., Vieira, N.D.: Green synthesis of stable silver nanoparticles using Euphorbia milii latex. Colloids Surf. A 389(1-3), 134-137 (2011). https:// doi.org/10.1016/j.colsurfa.2011.08.040

25. Vidhu, V.K., Aromal, S.A., Philip, D.: Green synthesis of silver nanoparticles using Macrotyloma uniflorum. Spectrochim. Acta A Mol. Biomol. Spectrosc. 83(1), 392-397 (2011). https://doi. org/10.1016/j.saa.2011.08.051

26. Banerjee, P., Satapathy, M., Mukhopahayay, A., Das, P.: Leaf extract mediated green synthesis of silver nanoparticles from widely available Indian plants: synthesis, characterization, antimicrobial property and toxicity analysis. Bioresour. Bioprocess. 1, 1-10 (2014). https://doi.org/10.1186/s40643-014-0003-y

27. Iravani, S.: Green synthesis of metal nanoparticles using plants. Green Chem. 13, 2638-2650 (2011). https://doi.org/10.1039/ c1gc15386b

28. Ajitha, B., Reddy, A.K., Reddy, P.S.: Biosynthesis of silver nanoparticles using Momordica charantia leaf broth: evaluation of their innate antimicrobial and catalytic activities. J. Photochem. Photobiol. B Biol. 146, 1-9 (2015). https://doi.org/10.1016/j.jphot obiol.2015.02.017

29. Patil, R.S., Kokate, M.R., Kolekar, S.S.: Bioinspired synthesis of highly stabilized silver nanoparticles using Ocimum tenuiflorum leaf extract and their antibacterial activity. Spectrochim. Acta A Mol. Biomol. Spectrosc. 91, 234-238 (2012). https://doi. org/10.1016/j.saa.2012.02.009

30. Snega, S., Ravichandran, K., Baneto, M., Vijayakumar, S.: Simultaneous enhancement of transparent and antibacterial properties of $\mathrm{ZnO}$ films by suitable F doping. J. Mater. Sci. Technol. 31, 759-765 (2015). https://doi.org/10.1016/j.jmst.2015.03.001

31. Ravichandran, K., Snega, S., Jabena Begum, N., Swaminathan, K., Sakthivel, B., Rene Christena, L.: Enhancement in the antibacterial efficiency of $\mathrm{ZnO}$ nanopowders by tuning the shape of the nanograins through fluorine doping. Superlattice Microstruct. 69, 17-28 (2014). https://doi.org/10.1016/j.spmi.2014.01.020

32. Nikparast, Y., Saliani, M.: synergistic effect between phyto-synthesized silver nanoparticles and ciprofloxacin antibiotic on some pathogenic bacterial strains. J. Med. Bacteriol. 7, 36-43 (2018)

33. Sondi, I., Salopek-Sondi, B.: Silver nanoparticles as antimicrobial agent: a case study on E. coli as a model for Gram-negative bacteria. J. Colloid Interface Sci. 275(1), 177-182 (2004). https://doi. org/10.1016/j.jcis.2004.02.012

Publisher's Note Springer Nature remains neutral with regard to jurisdictional claims in published maps and institutional affiliations. 


\section{Affiliations}

\section{Venilla Selvaraj ${ }^{1}$ S Suresh Sagadevan ${ }^{2} \cdot$ Lakshmipathy Muthukrishnan $^{3} \cdot$ Mohd. Rafie Johan $^{2} \cdot$ Jiban Podder $^{4}$}

$\triangle$ Suresh Sagadevan drsureshnano@gmail.com

1 Department of Physics, Jayaraj Annapackiyam College for Women (Autonomous), Periyakulam, Tamilnadu 625 605, India

2 Nanotechnology and Catalysis Research Centre, University of Malaya, 50603 Kuala Lumpur, Malaysia
Leather Process Technology, Tannery Division, CSIR-Central Leather Research Institute (CLRI), Adyar, Chennai, Tamilnadu 600 020, India

4 Department of Physics, Bangladesh University of Engineering and Technology, Dhaka 1000, Bangladesh 